\title{
Pollination drop withdrawal in Juniperus communis: response to biotic and abiotic particles
}

\author{
Mugnaini $^{1}$ Serena, Massimo Nepi ${ }^{1 *}$, Massimo Guarnieri ${ }^{1}$, Beti Piotto $^{2}$ and Ettore \\ PACINI $^{1}$ \\ ${ }^{1}$ Dipartimento di Scienze Ambientali “G. Sarfatti”, Università di Siena, Via P.A. Mattioli 4, 53100 Siena, Italia. \\ ${ }^{2}$ Dipartimento Protezione della Natura, Agenzia per la Protezione dell' Ambientale e per I Servizi Tecnici (APAT), \\ Via Curtatone 3, 0085 Roma, Italy.
}

\begin{abstract}
Formation of the pollination drop (PD) in Juniperus communis, and the response to deposition of conspecific pollen and other particulate material is described. The PD persisted for about 12 days if not pollinated, and formed again after removal for up to four consecutive days. After pollination with viable conspecific pollen the PD retracted quickly and did not form again. Partial withdrawal occurred after deposition of other biological and nonbiological material. These results suggest that there is an aspecific mechanism, particle size dependent, that induces partial PD withdrawal. Complete PD withdrawal is presumably under the control of a biochemical molecular mechanism triggered only by viable conspecific pollen.
\end{abstract}

Key words: female cone, Gymnosperms, ovule, pollen, pollination drop

\section{INTRODUCTION}

In most Gymnosperms, pollen lands on the surface of the PD, rehydrates instantly, and enters the ovule as the drop retracts. The destination of pollen is the nucellar surface. It is now known that PDs, cones and plant organs specialized for pollination enhance and facilitate pollen capture (Nicklas 1985; Buchmann et al. 1989, GreEnWOoD 1986; Owens et al. 1998). The mechanisms of PD secretion and withdrawal are not clear (Singh 1978; Chesnoy 1993). Research on this topic is scanty and largely cytological. Biochemical and ecological aspects are generally neglected, as observed by CHESNOy (1993) in her review of the subject. The aim of this study was to obtain information about PD withdrawal in Juniperus communis L. (Cupressaceae), and to determine whether physical contact of non-pollen substances can influence PD withdrawal. This work is part of a research programme on the reproductive biology and low reproductive efficiency of Mediterranean junipers (MugNaINI et al. 2004).

* Corresponding author: phone +390577232867; fax: +390577232860; e-mail: nepim@unisi.it

\section{MATERIALS AND METHODS}

Plants of Juniperus communis used for this research grew close to Greve in Chianti (Florence province) at $\mathrm{N} 4836067,14$; E 200315,07 and $184.1 \mathrm{~m}$ of altitude. Material was collected from 20 plants of approximately the same age and height (about $2 \mathrm{~m}$ ).

PD volume and pollination experiments - Branches $3-5 \mathrm{~cm}$ long with female cones close to PD secretion were collected in the study areas the evening before the experiments and kept in the laboratory. Branches were inserted in vials containing water, and maintained overnight at $15^{\circ} \mathrm{C} \pm 1$ and $52 \% \pm 5 \mathrm{RH}$. Next morning branches bearing female cones without PD were discarded. Female cones were only used for experiments on the first day of PD exposure. We used an eyelash mounted on a wood stick with paraffin to collect pollen and deposit it by contacting the PD. Contact with the eyelash alone did not stimulate withdrawal of the PD. For the pollination trials we used: a) viable conspecific pollen collected soon after pollen sac opening (diameter $20 \mu \mathrm{m}$ ); b) dead conspecific pollen, killed by heat $\left(105^{\circ} \mathrm{C}\right.$ for $\left.12 \mathrm{~h}\right)$; c) particles of silica gel in two size ranges $(10-15 \mu \mathrm{m}$ and 63$200 \mu \mathrm{m})$. A stereomicroscope with micrometer eye piece was used to measure volume changes in 
"undisturbed" PD for a period of 48 hours. With the same method we observed volume changes 3 hours after pollination trials.

\section{RESULTS}

Under laboratory conditions, "undisturbed" PDs persisted for up to 12 days. Average PD diameter was $0.31 \mathrm{~mm}$, about $4-5$ times larger than that of the micropyle $(0.07 \mathrm{~mm})$. Mean volume on the first day of emission was $0.02 \mathrm{~mm}^{3}$ (range $\left.0.002-0.122 \mathrm{~mm}^{3}\right)$. The volume of unpollinated PDs followed for 48 hours fluctuated slightly in time under uniform laboratory conditions. PD touched with an uncharged eyelash did not retract or change in volume. Withdrawal only occurred when powdery material adhered to its surface (Fig. 1). When pollen of Juniperus communis was applied, some grains went directly into the PD while others remained on the surface, moving to the lowest point of the PD along the surface.
Three hours after deposition of the different materials on the PD, it was possible to distinguish three different responses: complete withdrawal when $\mathrm{PD}$ volume dropped to 0 , partial withdrawal when PD volume decreased significantly but did not drop to 0 , no withdrawal when there was no significant variation in PD volume or a volume increase (Fig. 1). Complete PD withdrawal was registered in a higher number of drops pollinated with $J$. communis viable pollen; the withdrawal was evident already after $30 \mathrm{~min}$. Partial withdrawal is frequent in drops pollinated with not viable pollen and 10-15 $\mu \mathrm{m}$ silica gel. No withdrawal was registered only in the control drops and in those treated with 60-200 $\mu \mathrm{m}$ silica gel. In the latter treatment there was a volume increase in $8 / 12$ cases.

\section{DISCUSSION}

The process of $\mathrm{PD}$ withdrawal has rarely been studied. Different species of gymnosperms respond differently to pollen deposition, in some

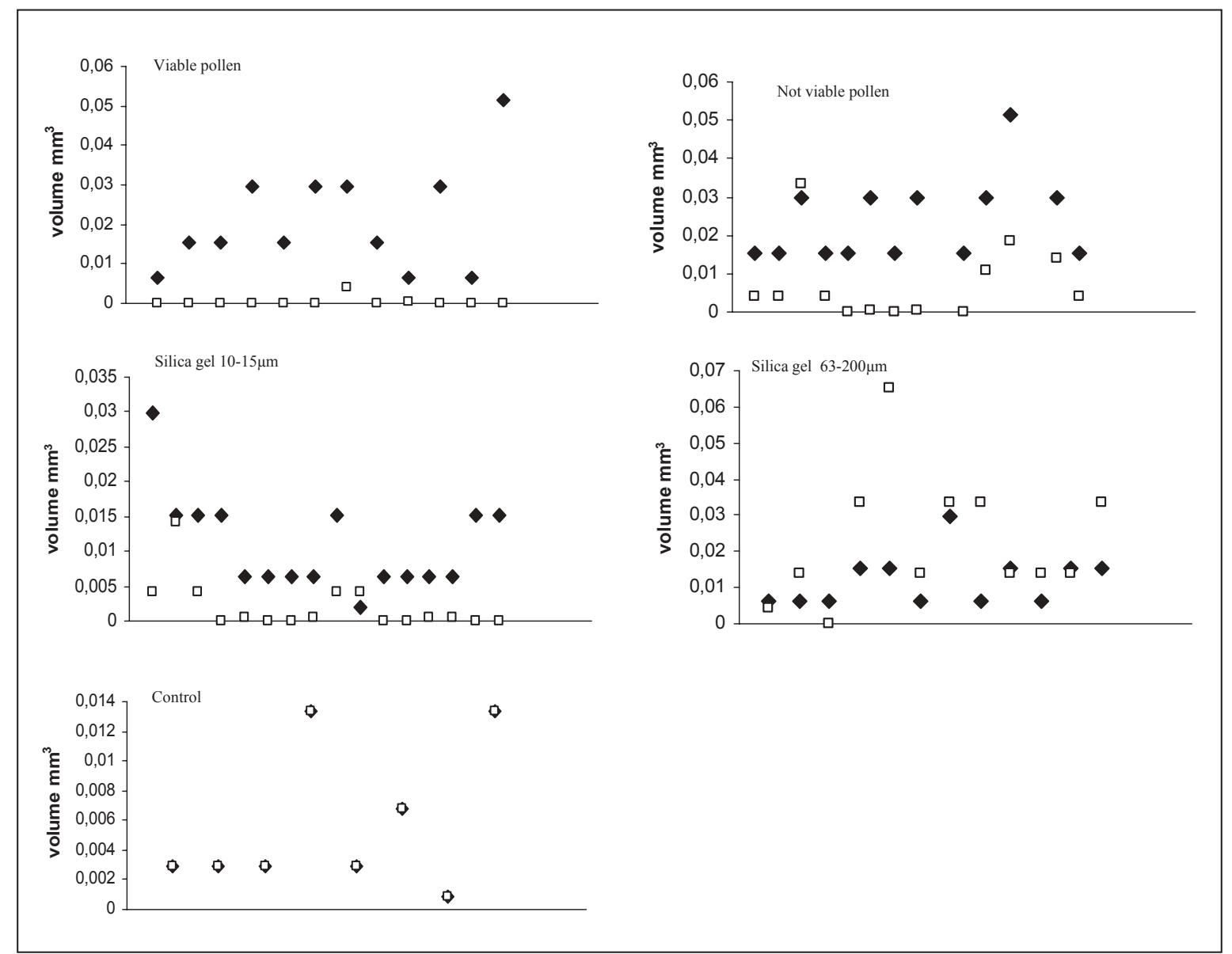

Fig. 1 - Effects of deposition of different powdery material on volume of pollination drop (PD). Black squares indicate PD volume before treatment, white squares that $3 \mathrm{~h}$ after treatment. In the control treatment there is no variation in PD volume and the two markers overlap. 
cases PD withdrawal results simply by evaporation (Tomlinson et al. 1991; TomLinson 1997). Our results with J. communis suggest that withdrawal of the PD occurs in two phases that may occur simultaneously or sequentially. A first phase involves partial withdrawal and occurs whenever particles of certain size are deposited on the PD surface, irrespective of their biological or abiotic nature, suggesting that at least at first, the mechanism of withdrawal is linked to an aspecific physical stimulus. However it seems that in this first phase the size of particles is selected; inorganic particles $10-15 \mu \mathrm{m}$ in size induce partial withdrawal of the drop whereas larger ones (63-200 $\mu \mathrm{m})$ have no effect. According to our experiments the conclusion reported by TomLinson et al. (1997) that inorganic material does not stimulate PD withdrawal may be affected by the large size of the particles used in their experiments (glass Balloti spheres, diameter about $75 \mu \mathrm{m}$ ). The second phase determines total withdrawal and seems to be completed only if viable conspecific pollen lands on the drop; this suggests the existence of a biochemical-molecular mechanism which requires a biological particle, such as pollen, and which does not respond to the stimulus of non viable pollen or abiological particles. It therefore seems that the drop may respond differently to stimuli determined by deposition of different particles.

Acknowledgements - This research was financed by APAT (Rome, Italy).

\section{REFERENCES}

Buchmann S.L, O'rourke M.K., Nicklas K.J., 1989 - Aerodynamics of Ephedra trifurca. III Selective pollen capture by pollination droplets. Botanical Gazette, 150: 122-131.

Chesnoy L., 1993 - Les secretions dans la pollinisation des Gymnospermes. Acta Botanica Gallica, 140: $145-156$

GrEENwOOD M.S., 1986 - Gene exchange in loblolly pine: the relation between pollination mechanism, female receptivity and pollen availability. American Journal of Botany, 73: 1443-1451.

Mugnaini S., Nepi M., Pacini E., Sapia L., Piotto B., 2004 - I ginepri come specie forestali pioniere: efficienza riproduttiva e vulnerabilità. APAT, Roma.

NICKLAS J., 1985 - The aerodynamics of wind pollination. Botanical Review, 51: 328-387.

Owens J.N., Takaso T., Runions C.J., 1998 - Pollination in conifers. Trends in Plant Science, 3: 479. 485.

SingH H. 1978 - Embryology of gymnosperms. Gebrüder Borntraeger, Berlin.

Tomlinson P.B., Braggins J.E., Rattenbury J.A., 1991 - Pollination drop in relation to cone morphology in Podocarpaceae: a novel reproductive mechanism. American Journal of Botany, 78: 12891303.

Tomlinson P.B., Braggins J.E., Rattenbury J.A., 1997 - Contrasted pollen capture mechanisms in Phyllocladaceae and certain Podocarpaceae (Coniferales). American Journal of Botany, 84:214-223.

Received November $30^{\text {th }} 2006$; accepted January $30^{\text {th }} 2007$ - 